\title{
Leptin attenuates the growth of rabbit mesenchymal stem cells via the extracellular signal-regulated kinase signaling pathway
}

\author{
LIPING SU ${ }^{1}$, QIAO QIAO ${ }^{2}$, RUIFENG $\mathrm{LI}^{3}$ and HUIGUANG WU ${ }^{4}$ \\ ${ }^{1}$ School of Basic Medical Science, Inner Mongolia Medical University; ${ }^{2}$ Obstetrics and Gynecology Department, \\ The Affiliated Hospital of Inner Mongolia Medical University; ${ }^{3}$ Department of Cervical Surgery, \\ The Second Affiliated Hospital of Inner Mongolia Medical University, Hohhot, Inner Mongolia 010010; \\ ${ }^{4}$ Animal Science College, Inner Mongolia University for The Nationalities, Tongliao, Inner Mongolia 028000, P.R. China
}

Received April 25, 2016; Accepted January 3, 2018

DOI: $10.3892 /$ etm.2018.5948

\begin{abstract}
When stimulated, mesenchymal stem cells (MSCs) may differentiate into chondroblasts, adipocytes or osteoblasts. Leptin is an adipocyte-derived hormone, which regulates food intake and glucose homeostasis. The aim of the present study was to identify the potential role of mitogen-activated protein kinase in the leptin-induced growth of rabbit bone MSCs (rBMSCs). Various concentrations of leptin were used to culture rBMSCs and the viability of cells was observed as well as alterations in the phosphorylation state of extracellular signal-regulated kinase 1/2 (ERK1/2), c-Jun N-terminal kinase and $\mathrm{p} 38$. It was revealed that the growth of leptin-treated rBMSCs was primarily inhibited by phosphorylated ERK1/2, which was mediated by the leptin receptor. In conclusion, the results of the present study demonstrated that leptin inhibits the growth of rBMSCs principally via the ERK1/2 signaling pathway.
\end{abstract}

\section{Introduction}

Bone marrow-derived mesenchymal stem cells (BMSCs) maybe readily obtained from bone marrow aspirates (1). The isolation of mesenchymal stem cells (MSCs) from the bone marrow of rats, cats, dogs, baboons, rabbits, pigs, goats and sheep has been standardized (2-4). Leptin is an adipocyte-derived hormone that regulates food intake, body weight and glucose homeostasis (5). Leptin regulates the

Correspondence to: Dr Huiguang Wu, Animal Science College, Inner Mongolia University for The Nationalities, 536 Huolinhe Street, Tongliao, Inner Mongolia 028000, P.R. China

E-mail: wuhuiguang1122@126.com

Dr Ruifeng Li, Department of Cervical Surgery, The Second Affiliated Hospital of Inner Mongolia Medical University, 1 Culture Street Camp Road, Hohhot, Inner Mongolia 010010, P.R. China E-mail: 54354631@qq.com

Key words: leptin, extracellular signal-regulated kinase1/2, leptin-induced rabbit mesenchymal stem cells release of insulin and glucagon, key hormones that regulate glucose homeostasis, by direct action on the $\beta$ - and $\alpha$-cells of the pancreatic islets, respectively (6). It has therefore been suggested that the adipo-insular axis is crucial for maintaining nutrient balance and that dysregulation of this axis contributes to obesity and diabetes (7).

Leptin acts on cells in the hypothalamus to reduce the production of orexigenic neuropeptides and reciprocally enhances the secretion of anorectic peptides, there by controlling food intake (8). In addition to its role as a satiety indicator, leptin has a wide range of biological functions, affecting reproduction, immunity, angiogenesis and anti-apoptotic effects (9).

Previous studies have focused on the effect of leptin on neural and embryonic stem cell growth (10); however, few studies have examined the effect of leptin on MSCs. In the present study, leptin was used to investigate the underlying molecular mechanisms affecting the growth potential of rabbit (r)BMSCs. The results revealed that leptin triggers the growth of rBMSCs via the extracellular signal-regulated kinase (ERK)1/2 signaling pathway.

\section{Materials and methods}

Chemicals and reagents. Unless otherwise specified, all chemicals and reagents were purchased from the Sigma-Aldrich (Merck KGaA, Darmstadt, Germany). Antibodies against Anti-Mouse immunoglobulin (Ig)G (cat. no. ab6789), GAPDH (cat. no. ab8245), cluster of differentiation (CD)44 (cat. no. ab119348), CD34 (cat. no. ab8158), inhibitor of phosphorylated (p)-ERK1/2 (U0126; cat. no. ab120241), ERK1/2 (cat. no. ab54230), c-Jun N-terminal kinases (JNK; cat. no. ab201624), p38 (cat. no. ab31828), p-p38 (cat. no. 45381), the ribosomal s6 kinase p90 ${ }^{\text {rsk }}$ (cat. no. ab32114), p-ERK1/2 (cat. no. ab50011), p-JNK (cat. no. ab46821), anti-leptin receptors (cat. no. ab104403) and p-p90 ${ }^{\text {rsk }}$ (cat. no. ab32413) were purchased from Abcam (Cambridge, MA, USA). MTT was purchased from Beyotime Institute of Biotechnology (Haimen, China). Opti-MEM I medium was purchased from Thermo Fisher Scientific, Inc. (Waltham, MA, USA).

Isolation and culture of rBMSCs. Bone marrow was obtained from a male neonatal New Zealand white rabbit $(0.75 \mathrm{~kg}$, 
1 month old; Vital River Laboratory Animal Technology Co., Ltd. Beijing, China). The rabbit was provided with free access to food and water and housed at $25^{\circ} \mathrm{C}$ with the humidity of $50-60 \%$ and a regular day-night cycle (12 h light/dark cycle). The present study was carried out in strict accordance with the Guidelines on the Care and Use of Laboratory Animals issued by the Chinese Council on Animal Research and the Guidelines of Animal Care (11). The rabbit was anesthetized via intraperitoneal injection with pentobarbital sodium (35 mg/kg; Sigma-Aldrich; Merck KGaA) prior to the retrieval of bone marrow and sacrifice. Bone marrow was flushed from the femur with low glucose Dulbecco's modified Eagle's medium (DMEM) as previously described (12). The harvested cells were cultured in an incubator at $37^{\circ} \mathrm{C}$ in an atmosphere containing $5 \% \mathrm{CO}_{2}$. Cell growth was monitored on days 2, 4 and 8 under an inverted phase contrast microscope (Nikon Corporation, Tokyo, Japan). The animal protocol was approved by The Inner Mongolia Medical University Experimental Animal Management Committee (Hohhot, China).

MTT assay. rBMSCs were seeded in 96-well plates at a density of $1 \times 10^{3}$ cells/well in DMEM supplemented with leptin at increasing concentrations $\left(0,10,10^{2}, 10^{3}\right.$ or $\left.10^{4} \mathrm{ng} / \mathrm{ml}\right)$. The control cells were cultured in DMEM containing $0.1 \%$ dimethyl sulfoxide (DMSO). MTT (20 $\mu 1$ with a final concentration of $0.5 \%$ ) was added to each well once daily for 9 days following treatment with leptin at $37^{\circ} \mathrm{C}$. Cells were subsequently incubated for $4 \mathrm{~h}$ at $37^{\circ} \mathrm{C}$ in the dark and $150 \mu \mathrm{l}$ DMSO was added to each well for $10 \mathrm{~min}$ to dissolve the formazan crystals. The absorbance was detected using a microplate reader (EXL800; Cole-Parmer, Vernon Hills, IL, USA) at $490 \mathrm{~nm}$. All experiments were repeated five times. The viability of leptin treated cells was expressed as the percentage of population growth plus the standard error of the mean relative to untransfected control cells. Cell growth was calculated as follows: Viability $=[$ (mean experimental absorbance-mean control absorbance)/mean control absorbance] x100.

Immunofluorescence. Cells were fixed and permeabilized with $0.5 \%$ Triton $\mathrm{X}-100$ for $15 \mathrm{~min}$ at room temperature and were subsequently blocked with $10 \%$ goat serum (Gibco; Thermo Fisher Scientific, Inc.) at $4^{\circ} \mathrm{C}$ overnight. Cells were incubated with anti-leptin receptors (1:400), CD44 (1:500) and CD34 (1:800) primary antibodies diluted in PBS at $37^{\circ} \mathrm{C}$ for $2 \mathrm{~h}$. The primary antibodies were detected by horseradish-conjugated (H+L) secondary antibodies (cat. no. 7074; 1:2,000; Cell Signaling Technology, Inc., Danvers, MA, USA) at $37^{\circ} \mathrm{C}$ for $1 \mathrm{~h}$. DAPI $(1 \mu \mathrm{g} / \mathrm{ml})$ was used to stain for $15 \mathrm{~min}$ at $37^{\circ} \mathrm{C}$. The fluorescence was captured using a fluorescence microscope at a magnification of $\mathrm{x} 200$. The experiments were performed five times.

Western blot analysis. Protein was isolated from rBMSCs treated with leptin with $10^{3} \mathrm{ng} / \mathrm{ml}$ using a Beyotime Cell Protein Extraction kit (Beyotime Institute of Biotechnology) according to the manufacturer's protocol. The total concentration of protein was determined using the bicinchoninic acid assay method. Proteins $(20 \mu \mathrm{g} / \mathrm{ml} ; 0.6 \mu \mathrm{g} /$ lane $)$ were separated by $12 \%$ SDS-PAGE and transferred to nitrocellulose membranes.
The membranes were blocked for 30 min with $5 \%$ fat-free milk at room temperature and incubated with the following primary antibodies: Anti-ERK1/2 (1:1,000), anti-p-ERK1/2 (1:800), anti-JNK (1:1,500), anti-p-JNK (1:1,000), anti-p38 $(1: 500)$, anti-p-p38 $(1: 800)$, anti- $\mathrm{p}^{90 \mathrm{rsk}}(1: 1,000)$ and anti-p-p ${ }^{90 \mathrm{rsk}}$ $(1: 1,000)$ for a minimum of $1 \mathrm{~h}$ at $37^{\circ} \mathrm{C}$. Membranes were subsequently incubated with horseradish-conjugated $(\mathrm{H}+\mathrm{L})$ secondary antibodies $(1: 4,000)$ at $37^{\circ} \mathrm{C}$ and developed using a Pierce $^{\mathrm{TM}}$ enhanced chemiluminescence plus western blotting substrate (cat. no. 32132; Thermo Fisher Scientific, Inc.). UVP VisionWorksLS software (UVP, LLC; DBA Analytik Jena US, Upland, CA, USA).

Leptin inhibition of rBMSCs. The phosphorylation status of the mitogen-activated protein kinases (MAPKs) ERK1/2, JNK and p38 were detected at 0,20,40 and 60 min following treatment with $10^{3} \mathrm{ng} / \mathrm{ml}$ leptin. The phosphorylation status $=$ the phosphorylation protein gray level/the protein gray level.

U0126 assay. Cells were incubated with U0126 (40 ng/ml), a p-ERK $1 / 2$ incubator, for $12 \mathrm{~h}$ at $37^{\circ} \mathrm{C}$. Leptin at a concentration of $10^{3} \mathrm{ng} / \mathrm{ml}$ or $200 \mu \mathrm{l}$ DMEM with $10 \%$ fetal bovine serum (FBS; Gibco; Thermo Fisher Scientific, Inc.) was then added and cell viability was measured at 0, 20, 40 and $60 \mathrm{~min}$. The MTT assay measured cell viability.

RNA interference and cell transfection. To confirm the role of leptin receptors in $\mathrm{rBMSCs}$, leptin receptor short hairpin RNA (shRNA) was used to silence the leptin receptor gene expression. The leptin receptor shRNA (sense, 5'-GGCUCU GUCUCCUUGAUAA-3'; and antisense, 3'-UUAUCAAGG AGACAGAGCC-5') was synthesized by Shanghai GeneChem Co., Ltd. (Shanghai, China) and transfected into rBMSCs using Lipofectamine ${ }^{\circledR} 2000$ (Invitrogen; Thermo Fisher Scientific, Inc.) according to the manufacturer's protocol. Briefly, $1 \times 10^{5}$ cells were seeded into 6 -well plates containing an antibiotic-free Opti-MEM ${ }^{\mathrm{TM}} \mathrm{I}$ and incubated overnight at $37^{\circ} \mathrm{C}$. In each well, $5 \mu \mathrm{l}$ shRNA was mixed with $125 \mu \mathrm{l}$ Opti-MEM $^{\text {TM }}$ I. The mixture was then combined with a solution of $5 \mu \mathrm{l}$ Lipofectamine ${ }^{\circledR} 2000$ in $125 \mu$ l Opti-MEM I. Following a $20 \mathrm{~min}$ incubation period at room temperature, the mixture was applied to cells in an appropriate volume of Opti-MEM I to achieve a final concentration of $100 \mathrm{nmol} / \mathrm{l}$ for each shRNA. Following incubation for $6 \mathrm{~h}$ at $37^{\circ} \mathrm{C}$, Roswell Park Memorial Institute-1640 supplemented with fetal bovine serum (FBS; both Gibco; Thermo Fisher Scientific, Inc.) was added to the wells. Cells were cultured for an additional $24 \mathrm{~h}$ at $37^{\circ} \mathrm{C}$ prior to analysis.

Statistical analysis. Statistically significant differences among groups were determined by one-way analysis of variance and GraphPad Prism version 5 software (GraphPad Software, Inc., La Jolla, CA, USA) was used to analyze the data. When the overall $F$ test result of analysis of variance was significant, a multiple-comparison Tukey's post hoc test was used. Student's t-test was used in two-mean comparisons. Five independent replicates were performed for all experiments. $\mathrm{P}<0.05$ was considered to indicate a statistically significant difference. Data are presented as the mean \pm standard deviation. 
A

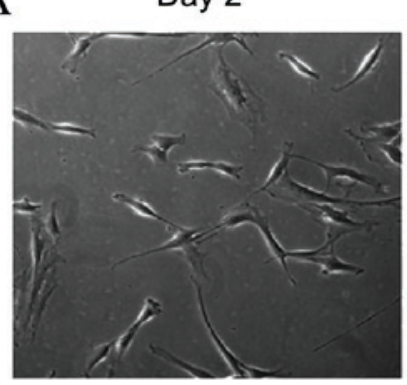

Day 4

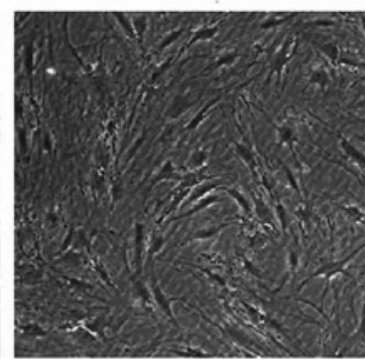

Day 8

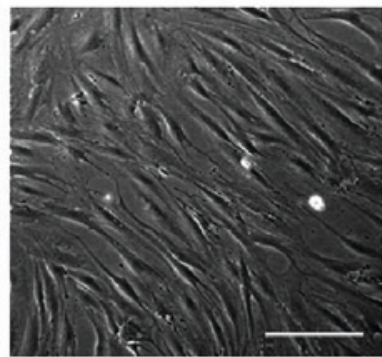

B

CD44

CD34
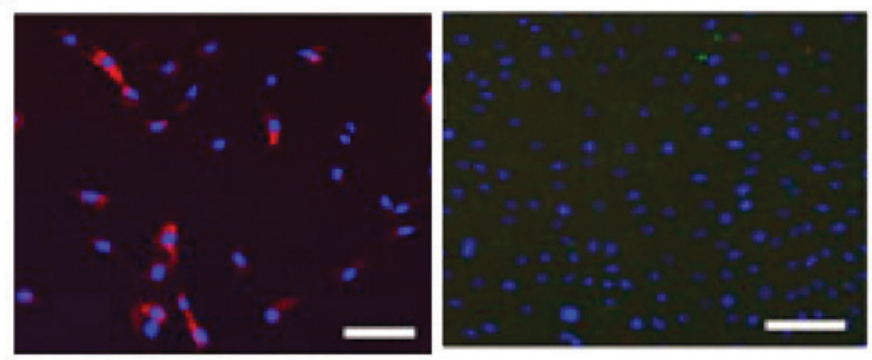

$\mathrm{C}$

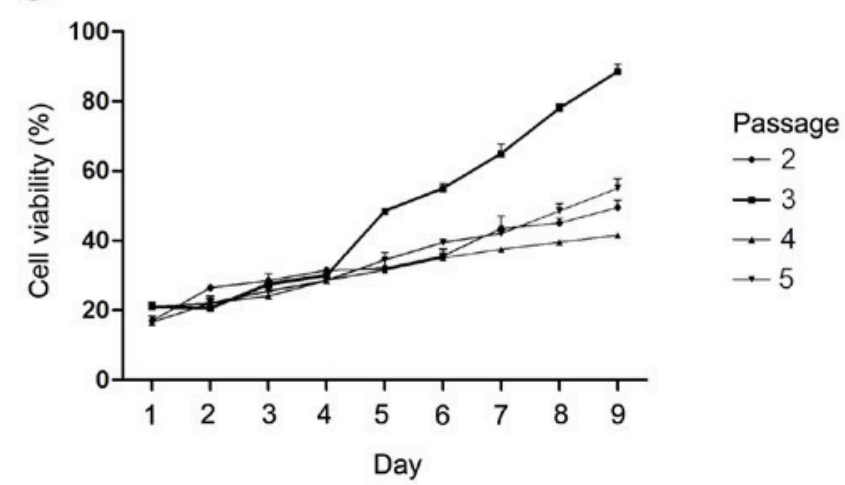

Figure 1. Identification of rBMSCs. (A) The morphology of rBMSCs at 2, 4 and 8 days following initial culture. Scale bar, $25 \mu \mathrm{m}$. (B) Immunofluorescent staining revealed the nucleus by DAPI staining (blue), and the expression of CD34 (red) and CD44 (red) in rBMSCs. (C) Cell viability. rMSC, rabbit mesenchymal stem cells; $\mathrm{CD}$, cluster of differentiation.

\section{Results}

Identification of rBMSCs. The morphology of rBMSCs was determined by visualizing the cells under a microscope (Fig. 1A). Cell density increased with duration of culturing. On day 2 , the cells reached $10 \%$ confluence. On day 8 , the cells displayed a uniform spindle shape and reached $80 \%$ confluence. To further identify the rBMSCs, CD34 and CD44 cell markers were detected using immunofluorescence. The cultured cells were positive for CD44 (red fluorescence; Fig. 1B); however, CD34 was not observed. Fig. 1C revealed the cell viability during the third passage was higher than that of other passages day 5 . Therefore, the third passage of cells had highest cell viability.

Optimal concentration and time for leptin-induced effects on rBMSCs. The cell viability of rBMSCs was determined for 1-9 days following the addition of leptin $\left(0,10,10^{2}, 10^{3}\right.$, or $\left.10^{4} \mathrm{ng} / \mathrm{ml}\right)$ to the culture medium from the fourth cell

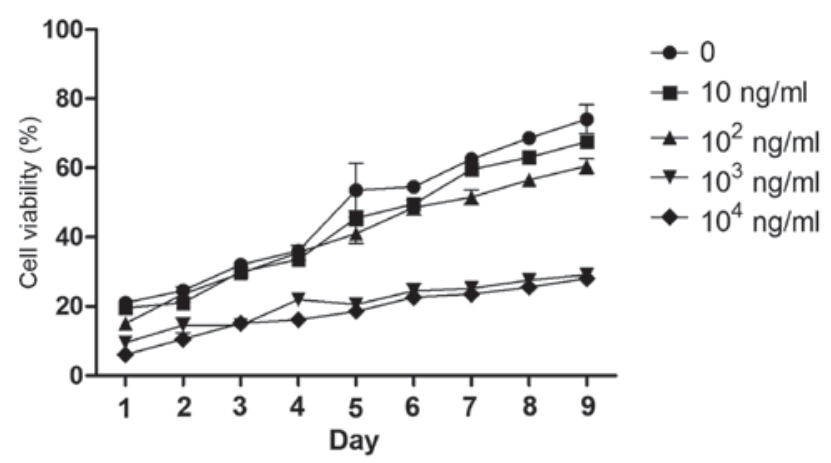

Figure 2. Leptin pretreatment inhibits the growth of rBMSCs. The cell viability of rBMSCs was determined by an MTT assay following pretreatment with leptin $\left(0,10,10^{2}, 10^{3}\right.$ and $\left.10^{4} \mathrm{ng} / \mathrm{ml}\right)$ for $1-9$ days. rMSC, rabbit mesenchymal stem cells.

passage (Fig. 2). Leptin caused minimum viability rate at $10^{3} \mathrm{ng} / \mathrm{ml}$ on the fifth day of treatment. Although leptin at 
A

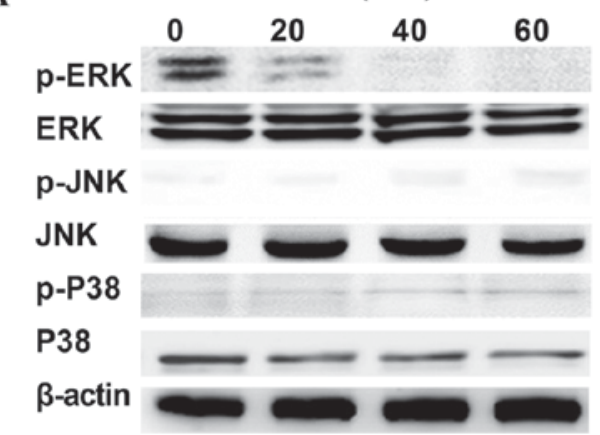

B

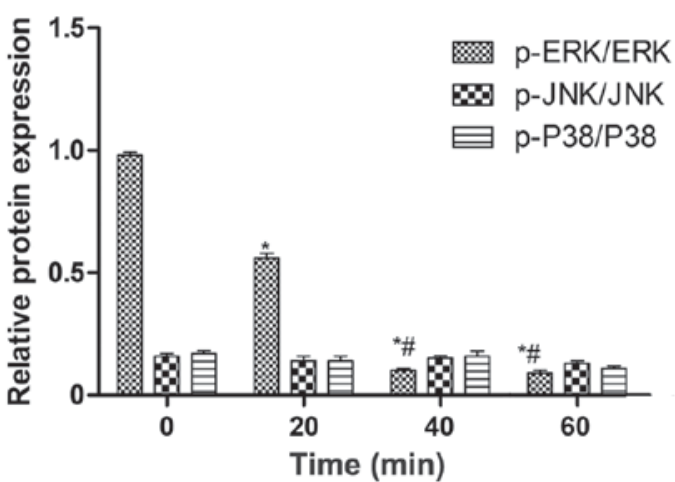

Figure 3. Effect of leptin on mitogen-activated protein kinase activation in rBMSCs. (A) Western blot analysis of the protein expression of total and phosphorylated ERK, JNK and p38. (B) The relative protein expression (phosphorylated/total) presented as the mean \pm standard deviation. This experiment was repeated 5 times. ${ }^{*} \mathrm{P}<0.05$ vs. $0 \mathrm{~min} .{ }^{*} \mathrm{P}<0.05$ vs. $20 \mathrm{~min}$. rMSC, rabbit mesenchymal stem cells; ERK, extracellular signal-regulated kinase; JNK, c-Jun N-terminal kinase; p-, phosphorylated.

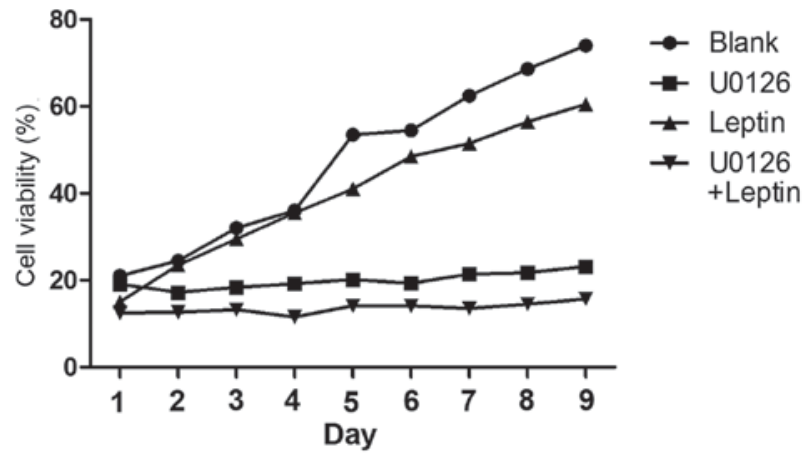

Figure 4. Cell viability of rBMSCs treated with U0126. Blank, medium only; Leptin, medium with leptin; U0126, medium with U0126; U0126+ leptin, medium with leptin and U0126. rMSC, rabbit mesenchymal stem cells.

$10^{4}$ and $10^{3} \mathrm{ng} / \mathrm{ml}$ caused the greatest decrease in cell viability at all time points, the lower concentration leptin was selected for subsequent experiments as this reduced cost and material usage.

Leptin inhibits the growth of rBMSCs via the ERK1/2 signaling pathway. To determine which pathway mediates the leptin-induced inhibition of rMSC growth, the phosphorylation states of the MAPKs, ERK1/2, JNK and p38 were detected at $0,20,40$ and $60 \mathrm{~min}$ following treatment with $10^{3} \mathrm{ng} / \mathrm{ml}$ of leptin (Fig. 3A). ERK1/2 phosphorylation was significantly
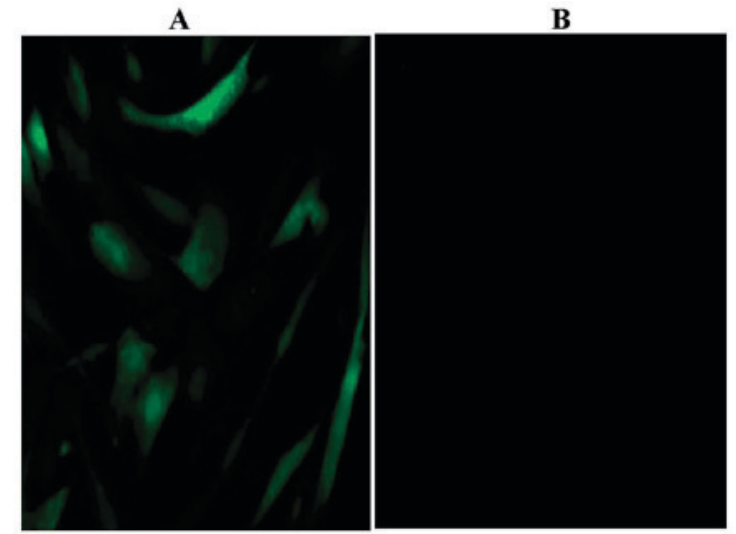

Figure 5. Expression of leptin receptors in cultured rBMSCs. (A) The expression of leptin receptors was detected my immunofluorescent staining (green) in rBMSCs. (B) The negative control. rMSC, rabbit mesenchymal stem cells.
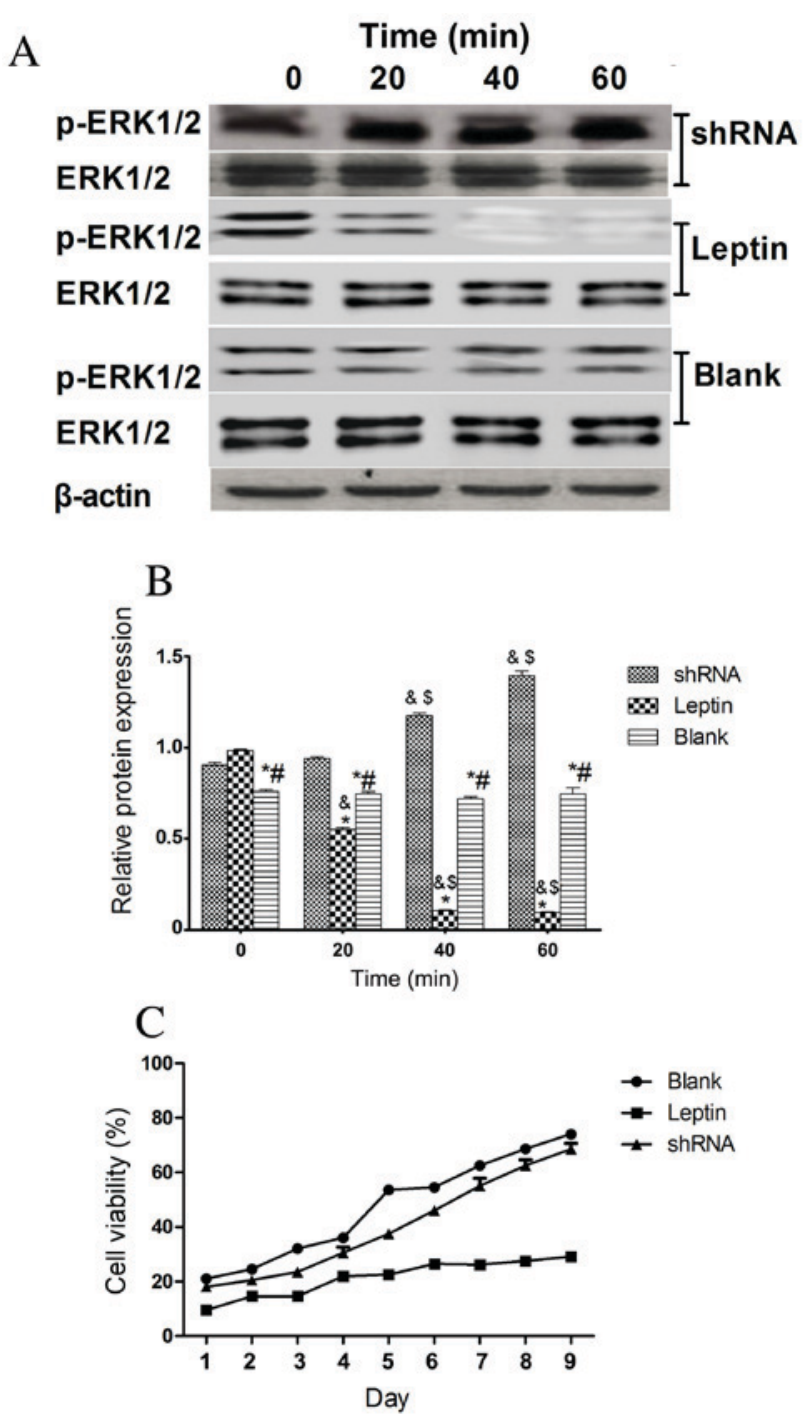

Figure 6. Effect of silencing leptin receptors with shRNA in rabbit mesenchymal stem cells. (A) The protein expression of total and phosphorylated ERK was detected by western blot analysis. (B) The results of the western blot analysis were quantified and the protein expression (phosphorylation/total) was presented as the mean \pm standard deviation. (C) Cell viability of rBMSC. This experiment was repeated 5 times. ${ }^{*} \mathrm{P}<0.05$ vs. the shRNA group. ${ }^{\#} \mathrm{P}<0.05$ vs. the leptin group. ${ }^{\&} \mathrm{P}<0.05$ vs. the 0 min group. ${ }^{\$} \mathrm{P}<0.05$ vs. the $20 \mathrm{~min}$ group. shRNA, short hairpin RNA; ERK, extracellular signal-regulated kinase; p-, phosphorylated. 
decreased at 40 min compared with the 0 and 20 min groups, whereas JNK and p38 phosphorylation was not (Fig. 3B). This suggests that the inhibition of ERK1/2 phosphorylation serves a key role in the ability of leptin to inhibit the growth of rBMSCs. To test this hypothesis, U0126 (a specific inhibitor of ERK1/2 phosphorylation) was used to blockERK1/2 expression. It was revealed that, in the presence of U0126, leptin $\left(10^{3} \mathrm{ng} / \mathrm{ml}\right)$ inhibits the growth of rBMSCs (Fig. 4).

Effect of silencing the leptin receptor in rBMSCs. Using immunocytochemistry, the expression of the leptin receptor (green) was detected in rBMSCs (Fig. 5). The leptin receptor was not detected in the blank control. To determine whether the effects of leptin were mediated by the receptor, leptin receptor gene expression was silenced using shRNA. Fig. 6A reveals that ERK1/2 was phosphorylated in rBMSCs with silenced leptin receptor genes and Fig. 6B demonstrates that there was no significant difference in ERK1/2 phosphorylation between each time point of the shRNA group. However, the cell viability of rBMSCs on days 1-9 was not significantly different in the shRNA knockdown group compared with the blank control group (Fig. 6C). This indicates that leptin receptors mediate the leptin-mediated inhibition of cell growth.

\section{Discussion}

Leptin is a member of the proinflammatory interleukin-6 family of cytokines (13). In keeping with its immune regulatory role, the long form of the leptin receptor is expressed in immune cells, including monocytes, T cells, dendritic cells, eosinophils, and B cells (14). Leptin receptors are also localized on adipose tissue cells $(15,16)$. Leptin binding to the leptin receptors stimulates stem cell proliferation, differentiation and cytokine secretion from adipose tissue (5).

In the present study, it was observed that leptin slows the growth of rBMSCs by inhibiting phosphorylation of the ERK1/2 branch of the MAPK signaling pathway. The optimal leptin concentration for inhibiting growth was $10^{3} \mathrm{ng} / \mathrm{ml}$. The effect of leptin was blocked by shRNA knockdown of the leptin receptors, indicating that the leptin-induced inhibition of growth in rBMSCs was mediated by the leptin receptors, which were expressed at high levels in rBMSCs.

To further investigate the mechanism by which leptin inhibits rMSC growth, the activity of the downstream signaling pathways of the leptin receptor were evaluated. MAPKs are a superfamily of serine/threonine kinases that includes ERK, JNK and p38 (16). These kinases are primarily associated with the activation of nuclear transcription factors that control cell proliferation, differentiation and apoptosis (17). The results of the present study suggest that leptin inhibits the growth of rBMSCs via the ERK signaling pathway. At 20-60 min following treatment with leptin the phosphorylation of ERK was inhibited, which indicates that inhibition is time-dependent.

In conclusion, the results of the present study indicate that leptin inhibits rMSC growth primarily through an ERK-dependent signaling pathway. These findings suggest that leptin maybe useful for inhibiting the number of rBMSCs. It may be useful to reduce the concentration of leptin in a clinical setting to promote rBMSCs proliferation. The present study only performed in vitro studies, further study is required and it may be useless to also performed in vivo studies.

\section{Acknowledgements}

Not applicable.

\section{Funding}

No funding was received.

\section{Availability of data and materials}

The data that support the findings of this study are available from $\mathrm{Dr} \mathrm{HW}$, but restrictions apply to the availability of these data, which were used under license for the current study, and so are not publicly available. Data are however available from the authors upon reasonable request and with permission of Dr HW.

\section{Authors' contributions}

LS and QQ performed all experiments. RL and HW performed statistical analysis of the data.

\section{Ethics approval and consent to participate}

The animal protocol was approved by The Inner Mongolia Medical University Experimental Animal Management Committee (Hohhot, China).

\section{Consent for publication}

Not applicable.

\section{Competing interests}

The authors declare that they have no competing interests.

\section{References}

1. Zhang $\mathrm{Y}$ and Wang W: Effects of bone marrow mesenchymal stem cell transplantation on light-damaged retina. Invest Ophthalmol Vis Sci 51: 3742-3748, 2010.

2. Zheng H, Martin JA, Duwayri Y, Falcon G and Buckwalter JA Impact of aging on rat bone marrow-derived stem cell chondrogenesis. J Gerontol A Biol Sci Med Sci 62: 136-148, 2007.

3. van Marion AM, Thiele J, Kvasnicka HM and van den Tweel JG: Morphology of the bone marrow after stem cell transplantation. Histopathology 48: 329-342, 2006.

4. Xu B, Zhang J, Brewer E, Tu Q, Yu L, Tang J, Krebsbach P, Wieland $\mathrm{M}$ and Chen J: Osterix enhances BMSC-associated osseointegration of implants. J Dent Res 88: 1003-1007, 2009.

5. Zheng Q, BanaszakL,Fracci S, Basali D, Dunlap SM, Hursting SD Rich JN, Hjlemeland AB, Vasanji A, Berger NA, et al: Leptin receptor maintains cancer stem-like properties in triple negative breast cancer cells. Endocr Relat Cancer 20: 797-808, 2013.

6. Zheng B, Jiang J, Luo K, Liu L, Lin M, Chen Y and Yan F: Increased osteogenesis in osteoporotic bone marrow stromal cells by overexpression of leptin. Cell Tissue Res 36: 845-856, 2015.

7. Tse HF, Yiu KH and Lau CP: Bone marrow stem cell therapy for myocardial angiogenesis. Curr Vasc Pharmacol 5: 103-112, 2007.

8. Noda T, Kikugawa T, Tanji N, Miura N, Asai S, Higashiyama S and Yokoyama M: Long-term exposure to leptin enhances the growth of prostate cancer cells. Int J Oncol 46: 1535-1542, 2015. 
9. Saucillo DC, Gerriets VA, Sheng J, Rathmell JC and Maciver NJ: Leptin metabolically licenses $\mathrm{T}$ cells for activation to link nutrition and immunity. J Immunol 192: 136-144, 2014.

10. Kurtovic S, Ng TT, Gupta A, Arumugaswami V, Chaiboonma KL, Aminzadeh MA, Makkar R, Dafoe DC and Talavera-Adame D Leptin enhances endothelial cell differentiation and angiogenesis in murine embryonic stem cells. Microvasc Res 97: 65-74, 2015.

11. Wang WZ, Yao XD, Huang XJ, Li JQ and Xu H: Effects of TGF- $\beta 1$ and alginate on the differentiation of rabbit bone marrow-derived mesenchymal stem cells into a chondrocyte cell lineage. Exp Ther Med 10: 995-1002, 2015.

12. Nokhbehsaim M, Keser S, Nogueira AV, Jäger A, Jepsen S, Cirelli JA, Bourauel C, Eick S and Deschner J: Leptin effects on the regenerative capacity of human periodontal cells. Int J Endocrinol 2014: 180304, 2014.

13. Cassano S, Pucino V, La Rocca C, Procaccini C, De Rosa V, Marone $\mathrm{G}$ and Matarese G: Leptin modulates autophagy in human CD4+CD25-conventional T cells. Metabolism 63: $1272-1279,2014$

14. Reis BS, Lee K, Fanok MH, Mascaraque C, Amoury M, Cohn LB, Rogoz A, Dallner OS, Moraes-Vieira PM, Domingos AI and Mucida D: Leptin receptor signaling in T cells is required for Th17 differentiation. J Immunol 194 5253-5260, 2015.
15. Dupuis L, Schuermann Y, Cohen T, Siddappa D, Kalaiselvanraja A, Pansera M, Bordignon V and Duggavathi R: Role of leptin receptors in granulosa cells during ovulation. Reproduction 147: 221-229, 2013.

16. Réus GZ, Vieira FG, Abelaira HM, Michels M, Tomaz DB, dos Santos MA, Carlessi AS, Neotti MV, Matias BI, Luz JR, et al: MAPK signaling correlates with the antidepressant effects of ketamine. J Psychiatr Res 55: 15-21, 2014.

17. Delhanty PJ, van der Eerden BC, van der Velde M, Gauna C, Pols HA, Jahr H, Chiba H, van der Lely AJ and van Leeuwen JP: Ghrelin and unacylated ghrelin stimulate human osteoblast growth via mitogen-activated protein kinase (MAPK)/ phosphoinositide 3-kinase (PI3K) pathways in the absence of GHS-R1a. J Endocrinol 188: 37-47, 2006.

This work is licensed under a Creative Commons Attribution-NonCommercial-NoDerivatives 4.0 International (CC BY-NC-ND 4.0) License. 